\title{
Investigating the synergy of integrated anaerobic digestion and photodegradation using hybrid photocatalyst for molasses wastewater treatment
}

\author{
Janet Mabuza $^{1} \cdot$ Benton Otieno $^{1} \cdot$ Seth Apollo $^{1} \cdot$ Boitumelo Matshediso $^{1} \cdot$ \\ Aoyi Ochieng ${ }^{1}$
}

Received: 31 January 2017 / Accepted: 22 July 2017/Published online: 1 August 2017

(C) Springer International Publishing AG 2017

\begin{abstract}
Anaerobic digestion (AD) can remove the high organic load of molasses wastewater (MWW), but is ineffective in removing the characteristic dark brown colour caused by biorecalcitrant melanoidin. Ultraviolet (UV) photodegradation, can mineralise the biorecalcitrants leading to complete colour removal, but with a high-energy input and low organic load removal. This study investigated the plausibility of integrating the two processes for organic load and colour reductions. Desk scale AD and photodegradation processes were carried out in batch reactors. A hybrid photocatalyst consisting of titanium dioxide $\left(\mathrm{TiO}_{2}\right)$ and zinc oxide $(\mathrm{ZnO})$ was used for photocatalytic degradation. Biodegradation at thermophilic conditions in the bioreactor achieved high total organic carbon (TOC) and chemical oxygen demand (COD) reductions of 80 and $90 \%$, respectively, but with an increased colour intensity. Contrastingly, UV photodegradation achieved a high colour reduction of $92 \%$ with an insignificant $6 \%$ TOC reduction, after $30 \mathrm{~min}$ of irradiation. During photodegradation, the mineralisation of the biorecalcitrant organic compounds led to the colour disappearance. The energy required for the TOC reduction was 40-fold higher than that required for the colour reduction in the same irradiation period, suggesting that the UV process was only suitable for colour reduction. Therefore, there is a possible synergy when the two processes are integrated, with $\mathrm{AD}$ preceding $\mathrm{UV}$, where $\mathrm{AD}$
\end{abstract}

Janet Mabuza

mabuzajanet@gmail.com

1 Centre for Renewable Energy and Water, Vaal University of Technology, Private Bag x021, Vanderbijlpark 1900, South Africa removes the high COD/TOC while UV removes the recalcitrant colour at a reduced cost.

Keywords Anaerobic digestion · Photodegradation · Energy demand $\cdot$ Molasses wastewater $\cdot$ Synergy

\section{Introduction}

Alcohol production from molasses is among the most polluting agro-based industries, generating a large amount of wastewater with high organic content (Satyawali and Balakrishnan 2008). Normally, for every litre of alcohol that is produced, about 15 litres of high-strength distillery effluent is generated (Wilkie et al. 2000; De Vrieze et al. 2014). In the distillation process, molasses is diluted and taken to a fermenter to produce bioethanol with the addition of yeast. The fermentation broth is filtered and then distilled to concentrate bioethanol. The final effluent after the distillation process is the molasses wastewater (Arimi et al. 2014; Chavan et al. 2006). Molasses wastewater (MWW) pollutes the aquatic ecosystem due to its dark brown colour, which cuts off light thereby preventing photosynthesis, leading to the death of aquatic plants. The high organic load [chemical oxygen demand (COD) of $80,000-100,000 \mathrm{mg} / \mathrm{L}]$ of the effluent leads to eutrophication, which further creates unwanted anaerobic conditions in the aquatic systems (Jai Shankar Pillai et al. 2012). MWW also affects agricultural crops in cases where it is directly disposed of into the soil by causing soil acidification (Navgire et al. 2012; De Vrieze et al. 2014). It is, therefore, of a necessity to effectively treat MWW for its high organic load and characteristic dark brown colour before discharge into receiving streams. 
Anaerobic digestion (AD) has been employed conventionally for the treatment of wastes such as MWW due to its ability to degrade high strength wastewater with minimal sludge production and energy recovery in the form of biogas (Arnaiz et al. 2003). The AD process, however, is incapable of complete removal of biorecalcitrant organic compounds such as colour, causing melanoidin and phenolic compounds found in MWW. These compounds, especially the melanoidins, have a high inhibitory antimicrobial activity and are, therefore, not removed during $\mathrm{AD}$ (Chandra et al. 2008; Liu et al. 2013). Melanoidins, which constitutes $2 \%$ of the MWW, are polymeric in nature with high molecular weight (usually $>5.0 \mathrm{kDa}$ ) making them anti-oxidative hence the recalcitrant nature (Liang et al. 2009; Liu et al. 2013). Moreover, in some instances, the melanoidin compounds undergo polymerisation during $\mathrm{AD}$ leading to the generation of $\mathrm{AD}$ effluents with a more intense dark colour (Mohana et al. 2009). The AD process, therefore, is only effective for organic load reduction with a minimal or negligible reduction in colour. Since AD alone cannot achieve effective MWW treatment, there is need to integrate it with other treatment methods such as advanced oxidation processes (AOPs), which can completely mineralize the recalcitrant organic pollutants and are considered as highly competitive water treatment technologies (Oller et al. 2011).

Photocatalytic degradation of MWW, an advanced oxidation treatment, has been reported to be effective for the complete removal of the biorecalcitrant melanoidins contained in MWW leading to the colour disappearance. This process, however, is ineffective for the removal of the high organic content of MWW and has, therefore, been recommended for application as a plausible post-treatment to AD (Otieno et al. 2016). Moreover, the widely used semiconductor oxide photocatalyst titanium $\left(\mathrm{TiO}_{2}\right)$ and zinc $(\mathrm{ZnO})$ despite having desirable properties such as low cost, chemical stability, and high resistance to photo-corrosion, still suffer from low quantum efficiency due to the rapid recombination of electron-hole pairs (Bechambi et al. 2015a; Jiang et al. 2013). The generated electrons react with water molecules leading to the production of highly reactive hydroxyl radicals $(\mathrm{OH} \cdot)$, which initiate micropollutant degradation in addition to direct hole attack (Arany et al. 2014). To reduce the recombination rate and improve quantum yield, $\mathrm{TiO}_{2}$ and $\mathrm{ZnO}$ have been modified through doping with metals or non-metals or coupling with other semiconductors (Bechambi et al. 2015b; Otieno et al. 2017). The coupling of $\mathrm{ZnO}$ with $\mathrm{TiO}_{2}$ has gained interest recently as it results in the formation of a hybrid semiconductor $\left(\mathrm{TiO}_{2}-\mathrm{ZnO}\right)$ with superior photocatalytic activity and stability (Behzadnia et al. 2015). Jonidi-Jafari et al. (2015) developed a $\mathrm{TiO}_{2}-\mathrm{ZnO}$ hybrid semiconductor photocatalyst, which showed an improved activity in the photodegradation of Diazinon as compared to $\mathrm{TiO}_{2}$ and $\mathrm{ZnO}$ on their own. The improved activity was due to increased quantum efficiency resulting from reduced recombination rate of electron-hole pairs and extended range of light absorption.

The capability of AD in treating MWW for the high organic content and its inability to remediate the characteristic dark colour is widely known. However, it is of a necessity to gather information on the efficiency of employing AOPs such as photocatalytic degradation alongside $\mathrm{AD}$, for colour and organic load elimination. Bench-scale and pilot-scale studies are important for information generation and development of technologies for new treatment processes. Such studies have been found to come in handy when investigating the possibility of combining two or more technologies for the effective treatment of wastewater (Oller et al. 2011). In this study, therefore, we report the separate treatment of MWW employing both $\mathrm{AD}$ and photocatalytic degradation using $\mathrm{TiO}_{2}-\mathrm{ZnO}$ hybrid, on a bench scale. Of special interest is the investigation of the plausibility of integrating the two processes for effective MWW treatment based on energy demand, and organic load and colour removal efficiencies.

\section{Methods}

\section{Materials}

Commercial molasses used for preparing MWW was outsourced from a local sugar milling company in Gauteng, South Africa (RSA) and kept at room temperature $\left(25^{\circ} \mathrm{C}\right)$. Cow dung used to prepare inoculum was obtained from a farm (Carletonville, RSA) and stored in a refrigerator at $4{ }^{\circ} \mathrm{C}$ before use, to minimise the decomposition of essential microbes. Zinc chloride $\left(\mathrm{ZnCl}_{2}, 97 \%\right)$, sodium hydroxide $(\mathrm{NaOH})$, and titanium (IV) oxide $\left(\mathrm{TiO}_{2}\right.$, peroxide P25) used for synthesising the hybrid photocatalyst were sourced from Sigma-Aldrich, RSA.

\section{Equipment}

The desk-scale lab experimental setup (Fig. 1a), for AD consisted of an anaerobic batch reactor, a peristaltic pump, and a water bath. The batch reactor was a cylindrically shaped vessel with a total volume of $4 \mathrm{~L}$ and operational volume of 3.5 L. The bioreactor was sealed with an airtight lid at the top. Mixing was achieved by circulating the wastewater using a peristaltic pump. The $\mathrm{AD}$ experiments were maintained at thermophilic temperatures $\left(55^{\circ} \mathrm{C}\right)$ by means of the water bath. Mariotte water displacement method was used to collect the biogas produced. A batch photoreactor of $500 \mathrm{~mL}$ capacity with a $12 \mathrm{~W}$ UVC lamp, 

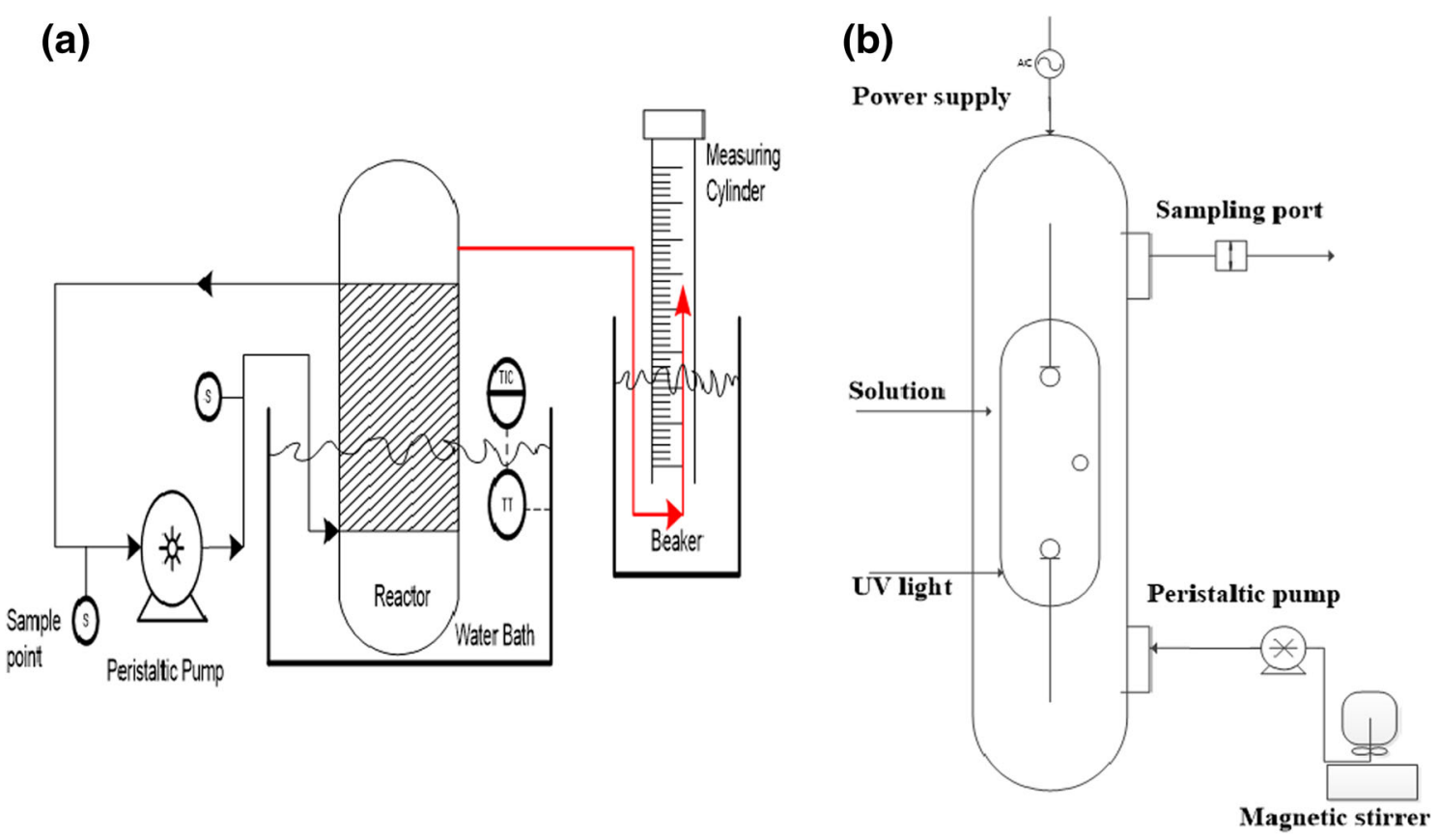

Fig. 1 Schematic representations of equipment setup for a anaerobic digestion, and $\mathbf{b}$ photodegradation

was sourced from Puritech, RSA, and used for photodegradation. The experimental setup for photodegradation consisted of a stirring plate, peristaltic pump, and a photoreactor (Fig. 1b).

\section{Catalyst synthesis and characterization}

The hybrid catalyst, $\mathrm{TiO}_{2}-\mathrm{ZnO}$ with $\mathrm{TiO}_{2}$ to $\mathrm{ZnO}$ ratio of 1:1 by weight was synthesised adopting a previous method employed by Jonidi-Jafari et al. (2015). In the method, $\mathrm{ZnO}$ was precipitated on the surface of commercial $\mathrm{TiO}_{2}$, from $\mathrm{ZnCl}_{2}$ and $\mathrm{NaOH}$. The obtained hybrid was dried, calcined at $500{ }^{\circ} \mathrm{C}$ in a muffle furnace and characterised. The characterisations were carried out using scanning electron microscopy-energy-dispersive X-ray spectroscopy, SEMEDX, (SEM-FEI Quanta 250 FEG ESEM with an integrated Oxford X-Max 20 EDX system), X-ray diffraction (XRD, Rigaku - Ultima IV, X-ray $40 \mathrm{kV}$, scan range $3^{\circ}-$ $90^{\circ}$ ), and a Jasco spectrofluorometer FP-8600 at an excitation wavelength of $425 \mathrm{~nm}$.

\section{Inoculum preparation and bioreactor operation}

The inoculum was prepared by diluting the obtained cow dung using distilled water forming a slurry, which was then fed with glucose and nutrients to enhance the active microorganism population. The inoculum was thereafter incubated at thermophilic conditions in the water bath while adding MWW gradually, for acclimatisation, until a stable of $\mathrm{pH}$ of about 7 was obtained. Molasses wastewater
(MWW) for $\mathrm{AD}$, was prepared by diluting the commercial molasses obtaining a substrate of desired initial concentration. The characteristics of the commercial molasses, inoculum and the prepared MWW for $\mathrm{AD}$ are given in Table 1. To start the biodegradation experiment, the bioreactor was fed with the initially prepared inoculum and MWW. The mixture was diluted obtaining an initial total organic carbon concentration (TOC) and chemical oxygen demand (COD) of 3200 and $6600 \mathrm{mg} / \mathrm{L}$, respectively.

Table 1 Characteristics of commercial molasses, inoculum and MWW for AD

\begin{tabular}{llll}
\hline Substrates & Parameters & Units & Value \\
\hline Commercial molasses & Dissolved solids & $\%$ & $76.2-81.2$ \\
& Total sugars as invert & $\%$ & Approx. 50 \\
& Invert sugar & $\%$ & Approx. 20 \\
& Sucrose & $\%$ & Approx. 30 \\
& Ash & $\%$ & $16 \mathrm{Max}$ \\
Inoculum & $\mathrm{pH}$ & & 6.0 \\
MWW for AD & $\mathrm{pH}$ & & $6.8-7.8$ \\
& $\mathrm{COD}$ & $\mathrm{mg} / \mathrm{L}$ & 444 \\
& $\mathrm{COD}$ & $\mathrm{mg} / \mathrm{L}$ & 6600 \\
& TOC & $\mathrm{mg} / \mathrm{L}$ & 3200 \\
& $\mathrm{pH}$ & & 7.04 \\
& Phosphates & $\mathrm{mg} / \mathrm{L}$ & 133.3 \\
& Nitrates & $\mathrm{mg} / \mathrm{L}$ & 7.14 \\
& Sulphates & $\mathrm{mg} / \mathrm{L}$ & 285.49 \\
\hline
\end{tabular}


During digestion, samples were periodically collected from the bioreactor and analysed to investigate operating parameters such as $\mathrm{COD}, \mathrm{pH}, \mathrm{TOC}$, biogas production, and nutrients reduction.

\section{Photodegradation studies}

For photodegradation purposes, the commercial molasses was again dissolved in distilled water to obtain a dark coloured MWW, but with minimal organic content (initial TOC concentration of $500 \mathrm{mg} / \mathrm{L}$ ), as compared to the MWW used in AD, which had an initial TOC of $3200 \mathrm{mg} /$ L. The synthesised catalyst was added to the prepared MWW at a catalyst loading of $1 \mathrm{~g} / \mathrm{L}$ in the dark and continuously stirred for $1 \mathrm{~h}$ ensuring adsorption-desorption equilibrium. After adsorption, the solution was transferred to the photoreactor via a peristaltic pump for irradiation. Samples were taken at predetermined time intervals, subsequently filtered with $0.45 \mu \mathrm{m}$ membrane filters and then analysed for colour and TOC. To monitor the mineralisation process during photodegradation, samples withdrawn at different time intervals were analysed for the presence of organic functional groups.

\section{Analytical methods}

Chemical oxygen demand (COD) analysis was carried out using closed reflux colorimetric method with potassium dichromate solution as oxidant and nano colour colorimeter. Colour analysis was determined from the absorbance at $\lambda_{\max }$ of $475 \mathrm{~nm}$ using a UV-Vis spectrophotometer (T80+ UV/VIS Spectrometer, PG Instruments Ltd). TOC was determined from a TOC analyser (TELEDYNE Tekmar), while nutrient analysis was done using ion chromatography (IC, 882 Compact). The biogas composition was analysed using gas chromatography (Trace 1310 GC). Change in organic functional groups during photodegradation due to the mineralisation of the organic recalcitrants was determined from Fourier to transform infrared (PerkinElmer FTIR/NIR).

\section{Findings}

\section{Catalyst characterization}

From the SEM image of $\mathrm{TiO}_{2}-\mathrm{ZnO}$, Fig. 2, a possible hybridization of $\mathrm{ZnO}$ and $\mathrm{TiO}_{2}$ can be seen from the well dispersed smaller $\mathrm{ZnO}$ particles on the surface of the bigger $\mathrm{TiO}_{2}$ particles, similarly observed by Jonidi-Jafari et al. (2015). The presence of $\mathrm{ZnO}$ nanoparticles well distributed on the surface of $\mathrm{TiO}_{2}$ nanoparticles is of importance as it retards charge recombination. $\mathrm{ZnO}$ has a lower electron

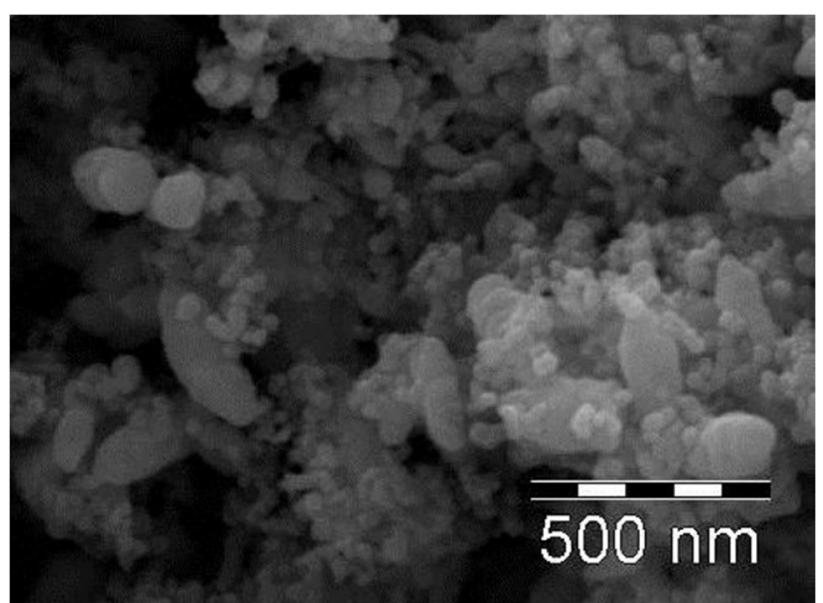

Fig. 2 SEM image of $\mathrm{TiO}_{2}-\mathrm{ZnO}$

affinity to organic chromophores as compared with $\mathrm{TiO}_{2}$. The nanoparticles of $\mathrm{ZnO}$ are regarded as highly efficient charge traps, providing enough distributed surface traps, thereby reducing the charge recombination with minimal hindrance to organics- $\mathrm{TiO}_{2}$ electron injection (Mozaffari et al. 2015). The XRD patterns in Fig. 3a and photoluminescence (PL) spectra Fig. 3b show the crystalline structure and the electron-hole pairs recombination rate of the catalysts, respectively. In the XRD patterns, peaks observed for the $\mathrm{ZnO}$ curve represents hexagonal wurtzite $\mathrm{ZnO}$ (Zhang et al. 2012; Bechambi et al. 2015a, b). The XRD curve for $\mathrm{TiO}_{2}$ has peaks characteristic of anatase crystalline phase (Bel Hadjltaief et al. 2016). Liao et al. (2008) observed a similar curve for $\mathrm{TiO}_{2}$ with a dominant peak corresponding to $2 \theta=25.3^{\circ}$ in the pattern and attributed it to a dominant anatase phase.

XRD peak intensity is proportional to the content of corresponding crystallites and also the sharpness of the peak indicates higher crystallinity (Ohtani 2010; Bechambi et al. 2015a, b). The $\mathrm{ZnO}$ catalyst with sharp and intense XRD peaks was more crystalline than $\mathrm{TiO}_{2}$ that had less intense peaks. Coupling $\mathrm{ZnO}$ with $\mathrm{TiO}_{2}$ to form $\mathrm{TiO}_{2}-\mathrm{ZnO}$ hybrid altered the crystallinity of both catalysts while maintaining the phase composition as seen with the reduction in peak heights, but with the retention of number and position of peaks. In the $\mathrm{TiO}_{2}-\mathrm{ZnO}$ nanocomposite, both the characteristic peaks of wurtzite $\mathrm{ZnO}$ and anatase $\mathrm{TiO}_{2}$ were gradually decreased. The crystalline phase of the hybrid was more composed of $\mathrm{ZnO}$ than $\mathrm{TiO}_{2}$ as observed with the high number of peaks corresponding to $\mathrm{ZnO}$. The XRD patterns thus indicate a successful preparation of $\mathrm{TiO}_{2}-\mathrm{ZnO}$ hybrid.

The PL spectra are generally used in the study of surface processes that involve electron-hole pairs of a catalyst. Electron-hole pair recombination resulting after a photocatalyst has been irradiated causes emission of photons, 

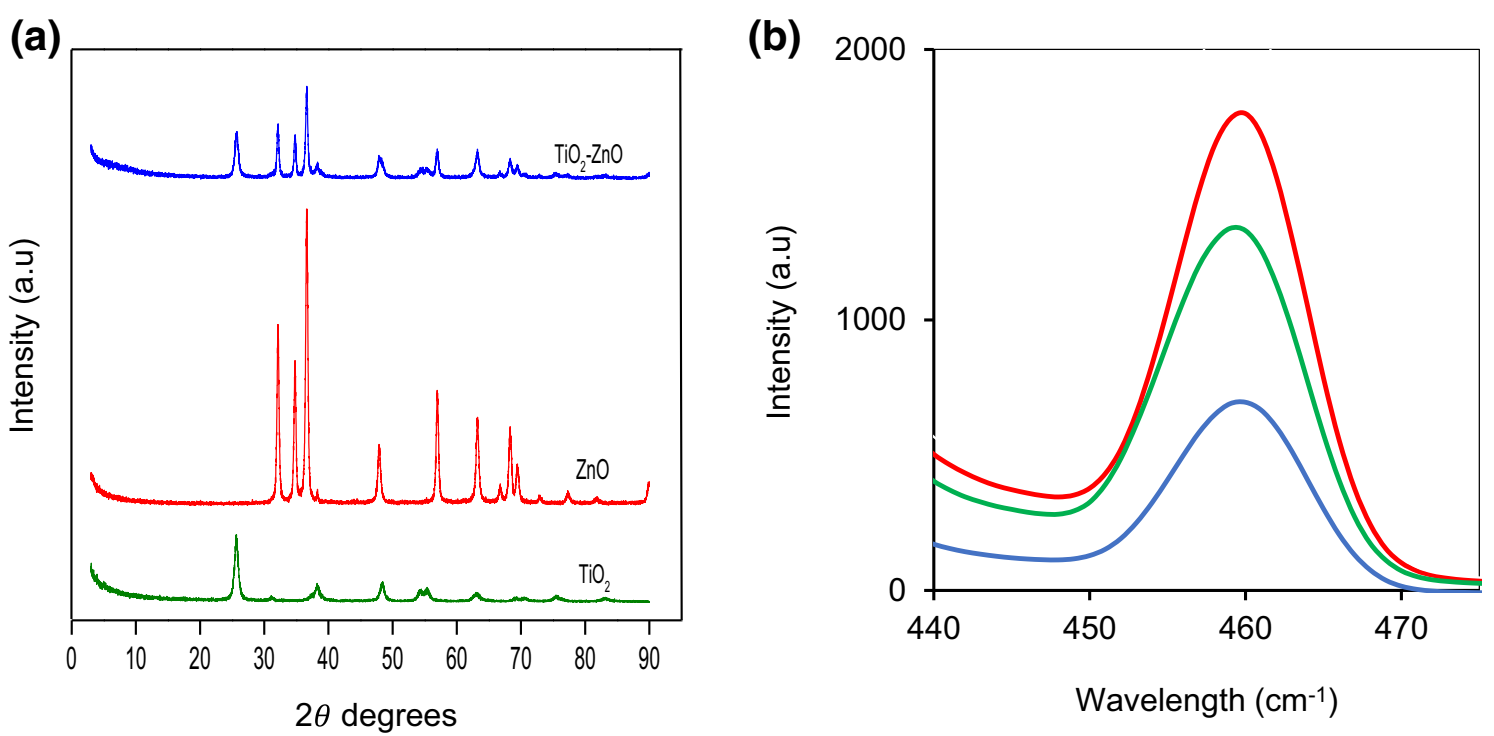

Fig. 3 a XRD patterns and b PL spectra of $\mathrm{TiO}_{2}$ (green), $\mathrm{ZnO}$ (red), and $\mathrm{TiO}_{2}-\mathrm{ZnO}$ (blue)

which results in photoluminescence. This behaviour is caused by the reverse radiative deactivation from the excited state (Xu et al. 2010). From the PL intensities in Fig. 3b, the hybrid $\mathrm{TiO}_{2}-\mathrm{ZnO}$ had the lowest intensity as compared to the pure $\mathrm{ZnO}$ and $\mathrm{TiO}_{2}$ thus indicating a reduced electron-hole pair recombination (Bechambi et al. $2015 \mathrm{a}, \mathrm{b})$. The reduced recombination is attributable to effective separation of electron/hole pairs in the hybrid system (Liu et al. 2010). In this system, transfer of electrons can take place from the conduction band (CB) of $\mathrm{TiO}_{2}$ to that of $\mathrm{ZnO}$, while hole transfer takes place from the valence band of $\mathrm{ZnO}$ to that of $\mathrm{TiO}_{2}$ (Wang et al. 2013). This leads to charge separation efficiency, increased charged carriers lifetime and efficient transfer of interfacial charge to adsorbed substrates (Habib et al. 2013).

\section{Anaerobic digestion}

\section{Effect of pH change on the production of biogas}

Figure 4 represents the daily amount of biogas produced and $\mathrm{pH}$ variations during anaerobic digestion of MWW. From previous studies, it has been reported that an optimum $\mathrm{pH}$ range for the growth of methanogens lies within $\mathrm{pH}$ of 6.0-8.0 (Apollo et al. 2013; Acharya et al. 2008). The steady increase in $\mathrm{pH}$ over time is a sign of proficient degradation of the organic compounds into methane and carbon dioxide. The best degradation rate of organic matter with the highest biogas volume of $700 \mathrm{~mL} /$ day produced was attained at a $\mathrm{pH}$ level lower than 7.5. These findings are consistent with previous

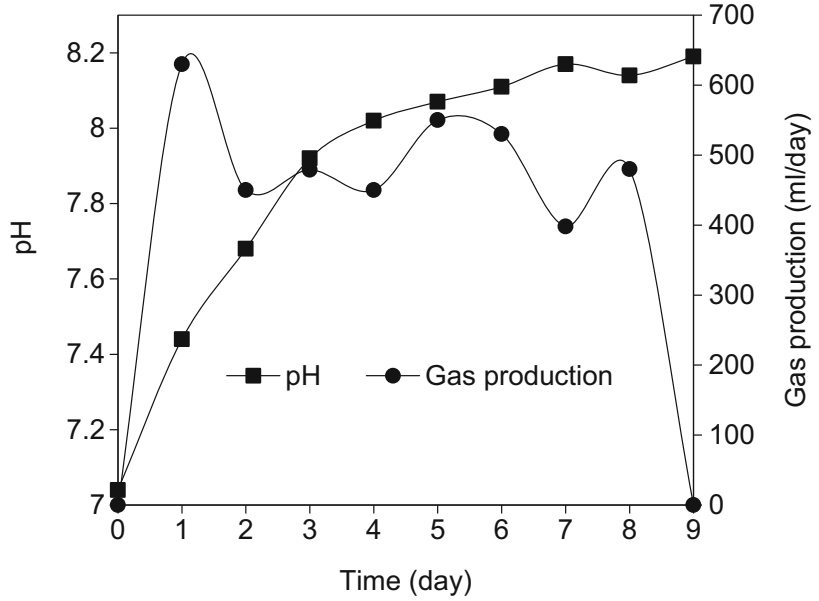

Fig. $4 \mathrm{pH}$ variations (square) and biogas production (circle) during anaerobic digestion of MWW

studies conducted by Li et al. (2011). The increase in $\mathrm{pH}$ may be attributed to the formation of ammonium nitrogen, which is generated during the degradation of proteins (Drosg 2013). According to Chen et al. (2008), methanogens have the lowest tolerance for ammonium nitrogen and are most likely to stop growing due to ammonia inhibition. The initial rapid increase in biogas production can be attributed to the readily available biodegradable organics in the feed, resulting in the high generation of methane during the initial stages of the process. The results also show that biogas production ceased on the 9th day at a substrate $\mathrm{pH}$ of 8.2. This may be due to the generation of the ammonium nitrogen and the depletion of the biodegradable organic substrate. 


\section{Cumulative biogas volume and biogas composition obtained during AD}

Figure $5 \mathrm{a}, \mathrm{b}$ shows the cumulative amount of biogas produced as a function of time and the biogas composition after 9 days. After 9 days of $\mathrm{AD}$, a total volume of $1839 \mathrm{~mL}$ of biogas was produced. The average composition of the biogas obtained was 91.74 and $8.26 \%$ for methane and carbon dioxide, respectively.

\section{TOC, COD, nutrient, and colour reductions during $\mathrm{AD}$}

The results obtained in this study show a significant difference in the percentage reduction of COD and TOC concentrations (Fig. 6). The reduction was due to the degradation and conversion of organic compounds into biogas (mainly $\mathrm{CH}_{4}$ and $\mathrm{CO}_{2}$ ). The achieved removal efficiencies of COD and TOC during the anaerobic treatment of MWW were 90 and $80 \%$, respectively. It was reported by Ibn Abubakar and Ismail (2012), that bioconversion of organics into biogas is highly influenced by microbial activity within the biodigester. Therefore, factors such as biogas volume, production rate, and methane composition (shown in Figs. 4, 5a, b, respectively) are indicative of the readily available organics for chemical oxidation. The AD system is thus very effective in removing the high organic load of MWW with the recovery of bioenergy in form of biogas.

The reduction of nutrient concentration during the anaerobic treatment of MWW is shown in Fig. 7. The general decrease in nitrates and phosphates indicate their consumption by the anaerobic bacteria for microbial cell

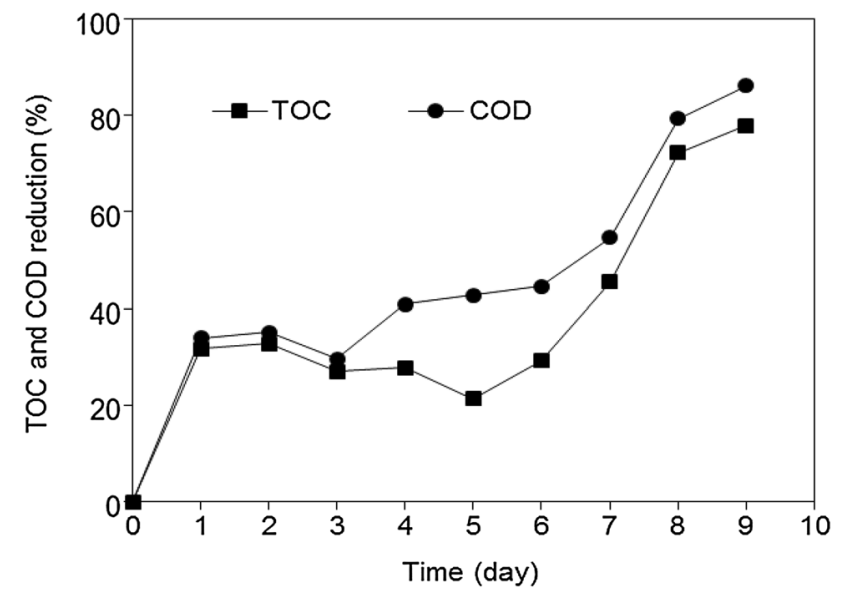

Fig. 6 Reduction in TOC (square) and COD (circle) during anaerobic digestion of MWW

growth (Jackson-Moss and Duncan 1990). Alternatively, the concentration reduction of nitrate could have been due to the denitrification process in the bioreactor (Acharya et al. 2008). In the present study, the sulphate concentration reduced from 285.49 to $47.5 \mathrm{mg} / \mathrm{L}$ on the 9 th day, resulting in a high sulphate removal rate. The high sulphate removal was also observed by Satyawali and Balakrishnan (2008) and was attributed to sulphate consumption by anaerobes as nutrients, and by sulphate reducing bacteria (SRB).

The colour intensity increased by $49 \%$ during the anaerobic process as depicted by the negative reduction in Fig. 8. The increased intensity could be due to the repolymerization of the colour causing melanoidin compounds (Liang et al. 2009). Apollo et al. (2013) also observed similar results with a $13 \%$ increase in colour intensity during $\mathrm{AD}$ of $\mathrm{MWW}$ at mesophilic conditions.
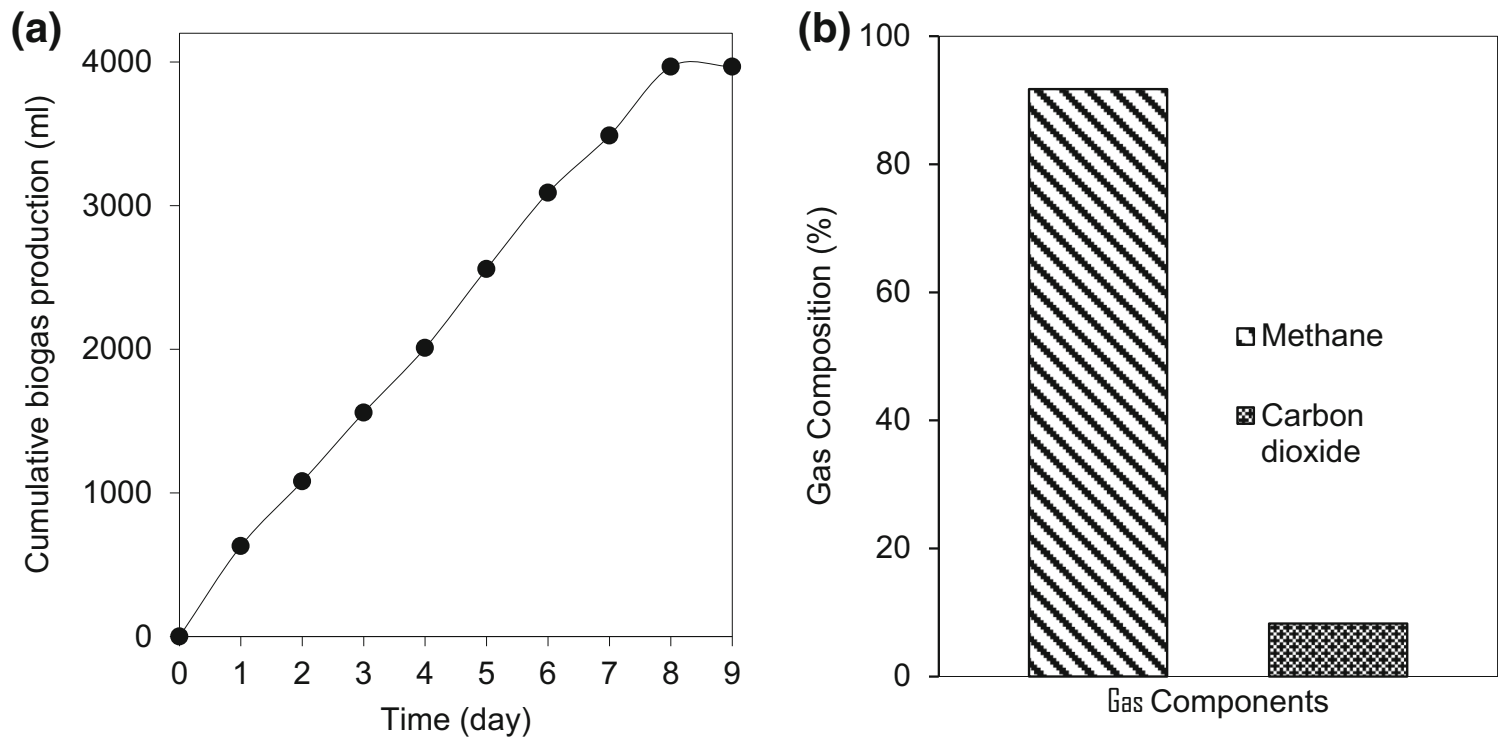

Fig. 5 a Cumulative amount of biogas produced during anaerobic digestion of MWW and $\mathbf{b}$ composition of the biogas produced 


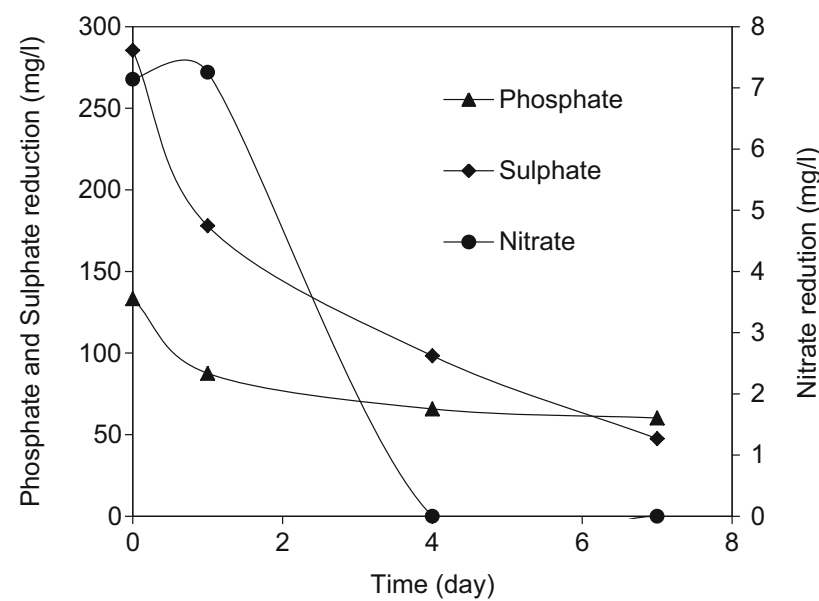

Fig. 7 Concentration of phosphate (triangle), sulphate (diamond), and nitrate (circle) during anaerobic digestion of MWW

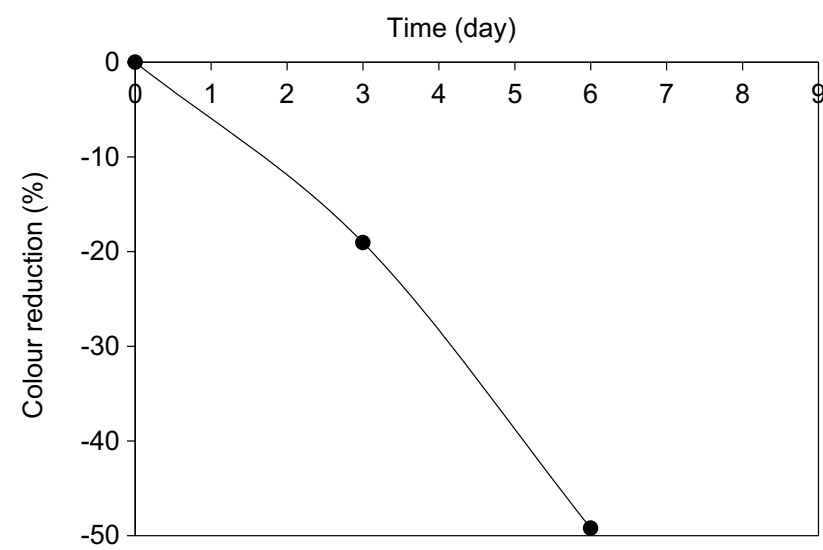

Fig. 8 Colour removal during the anaerobic treatment of MWW

The high increase observed in this study is attributable to the thermophilic conditions employed, which offers conditions similar to those leading to the formation and polymerization of melanoidins (Satyawali and Balakrishnan 2008). It is noticeable that biological treatment of MWW with AD is highly effective in reducing the high organic load, but very poor in colour removal. In this case, anaerobically-treated molasses wastewater effluent cannot be directly discharged into receiving streams without undergoing further treatment. For this reason, AD should be combined with a post-treatment method for colour abatement.

\section{Photodegradation studies}

\section{Colour reduction during photodegradation}

Unlike the anaerobic digestion, which was poor in colour reduction, photodegradation was found to be very effective

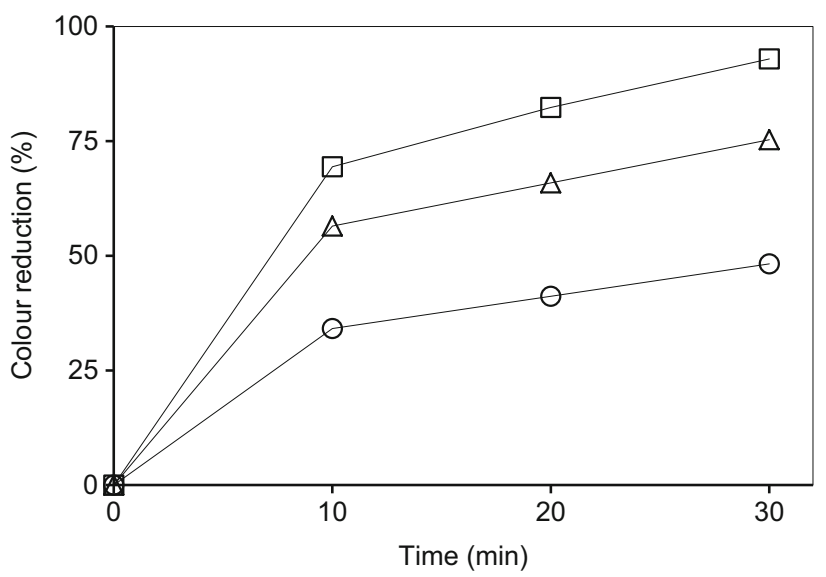

Fig. 9 Colour reduction during photodegradation of MWW using different catalysts; $\mathrm{TiO}_{2}-\mathrm{ZnO}$ (square), $\mathrm{TiO}_{2}$ (triangle) and $\mathrm{ZnO}$ (circle)

in colour reduction. The highest colour removal of $92 \%$ was achieved with the $\mathrm{TiO}_{2}-\mathrm{ZnO}$ hybrid as compared to $\mathrm{TiO}_{2}$ and $\mathrm{ZnO}$ which had 75 and $48 \%$ removals, respectively, after $30 \mathrm{~min}$ of irradiation, Fig. 9. The overall activity of the two semiconductors, when used in the hybrid, outweighed the sum activity of each signifying the realisation of a synergistic effect (Ohtani 2010). The hybrid photocatalyst had improved activity attributable to a reduced recombination rate of electron-hole pairs as observed in the PL analysis (see Fig. 3b). Coupling of $\mathrm{ZnO}$ and $\mathrm{TiO}_{2}$, therefore, resulted in a highly photoactive hybrid catalyst capable of removing MWW colour after a short irradiation time.

\section{Energy demand and mineralisation process}

Thirty minutes of UV light irradiation achieved colour reduction of $92 \%$, and only $6 \%$ of TOC removal was realised, Fig. 10a. Again, apart from synergy in colour reduction, another synergy for TOC reduction was revealed. Thus, AD complements photodegradation in TOC reduction, while photodegrading aides in colour reduction. Removal efficiency for organic pollutants under UV photocatalytic processes can be determined from the energy requirement of the process. Energy efficiency of the photocatalytic processes can be evaluated using electrical energy per order $\left(E_{\mathrm{o}}\right)$, which is defined as the required amount of electrical energy for the reduction of pollutant concentration in water. The $E_{\mathrm{o}}$ is convenient for comparing the effectiveness of removal of various pollution parameters such as TOC and colour for the same wastewater. Also for the purposes of process optimisation and operation, the knowledge of electrical energy requirement for removal of contaminants is of great interest. The electrical energy efficiency of the batch photodegradation process was determined from electrical energy per order $\left(E_{\mathrm{o}}\right)$ given by: 

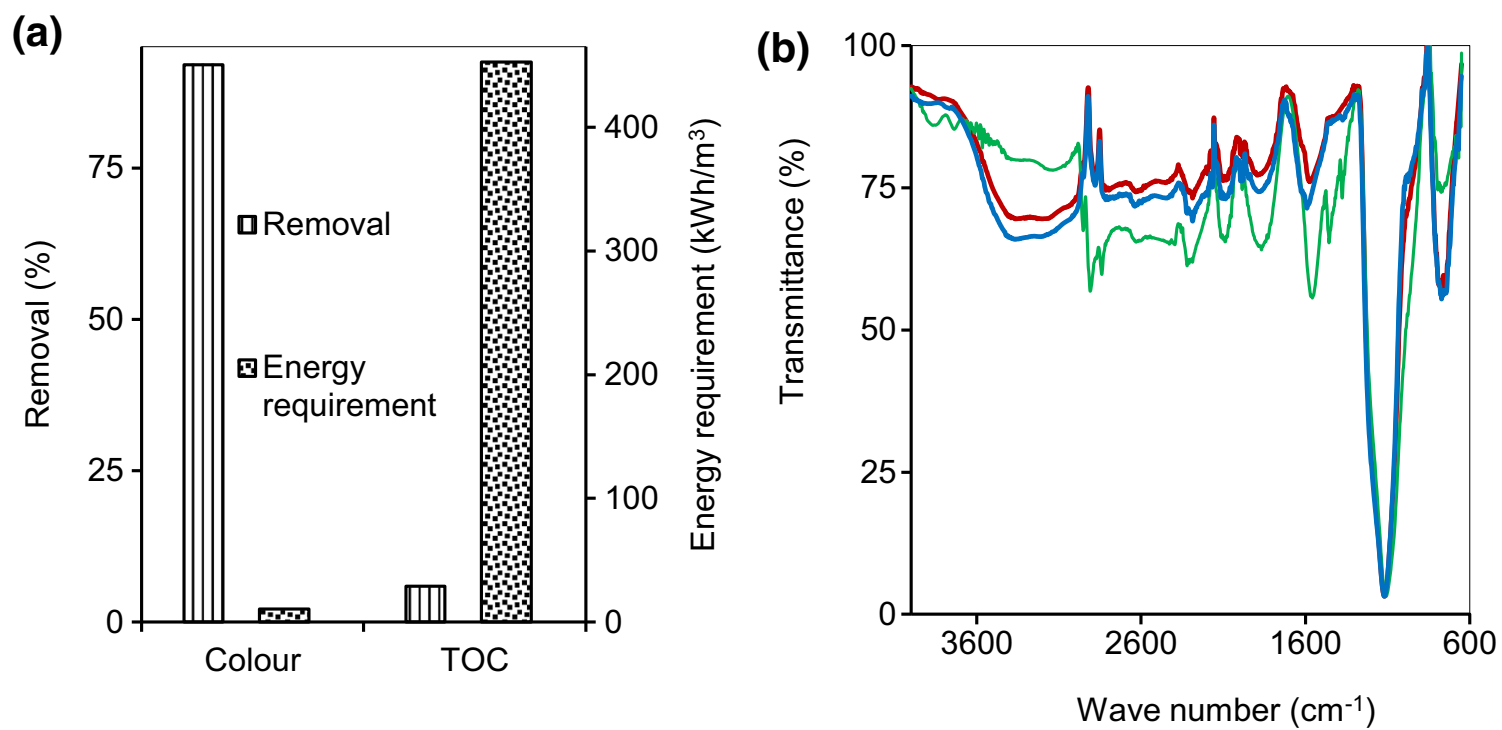

Fig. 10 a Comparison of percentage removal of energy requirement for colour and TOC and b FTIR spectra of MWW samples during photodegradation at varying time intervals, after $30 \mathrm{~min}$ (blue), $60 \mathrm{~min}$ (red), and 120 (green) min of irradiation

$E_{\mathrm{o}}=\frac{P \times t \times 1000}{V \times 60 \times \log \left(C_{\mathrm{i} /} C_{\mathrm{f}}\right)}$,

where $P$ is the lamp power $(\mathrm{kW}), t$ is the duration of irradiation (minutes), $V$ is the amount of wastewater degraded $(\mathrm{L}), C_{\mathrm{f}}$ and $C_{\mathrm{i}}$ are the final and initial concentrations, respectively, (Jonidi-Jafari et al. 2015). It was observed from Fig. 10a, that after 60 min of irradiation, the colour removal of $92 \%$ only required $10.42 \mathrm{kWh} / \mathrm{m}^{3}$ of energy as compared to $452.83 \mathrm{kWh} / \mathrm{m}^{3}$ of energy required for the $6 \%$ TOC removal during the same period, further demonstrating the high-energy requirement for UV photoreduction of TOC. Smaller values of are desirable as they signify efficient processes requiring less electrical energy in achieving the treatment goal (Shu et al. 2013).

The UV photodegradation process exhibited better and more efficient performance for the reduction of $\mathrm{MWW}$ colour as compared to the reduction of TOC. The colour causing melanoidin compounds were easily degraded under UV irradiation as compared to the more stable organic compounds responsible for TOC. Treatment of $\mathrm{MWW}$ using a UV photocatalyzed process for TOC reduction is, therefore, not feasible given the high electrical energy consumption resulting in high cost of operation. The higher the $E_{\mathrm{o}}$ value of a pollutant parameter, the costlier and more difficult it will be to remove that parameter, relative to other parameters with lower $E_{\mathrm{o}}$ values.

The FTIR spectra of MWW samples undergoing photodegradation at different time intervals (Fig. 10b), showed decreased peak intensities with increased irradiation time signifying mineralisation of the organic recalcitrant. After $60 \mathrm{~min}$ of irradiation, the peak intensities were reduced as compared to $30 \mathrm{~min}$ of irradiation, and upon continued irradiation, for another $60 \mathrm{~min}$, the characteristic broad $\mathrm{OH}$ peak appearing at $3000 \mathrm{~cm}^{-1}$ was almost diminished. Even though after $60 \mathrm{~min}$ all the colour had been removed, the observed broad characteristic $-\mathrm{OH}$ peak indicated the presence of organic compounds, which required further irradiation for complete mineralisation. Colour disappearance, therefore, does not signify complete mineralisation as in most cases the colour causing melanoidin is first broken down to colourless intermediates such as salicylic acid. Because of the high-energy demand by the UVC lamp, a prolonged period of irradiation to achieve complete mineralisation at high initial TOC will result in high cost of operation. This further highlights the importance of employing photocatalysis alongside other treatment processes such as biodegradation, where the high TOC will be first removed before the rapid removal of the biorecalcitrant colour-causing melanoidin compounds through UV photodegradation.

\section{Conclusion}

Anaerobic digestion is very effective for the removal of the high organic load from MWW, but ineffective in removing the characteristic dark brown colour caused by biorecalcitrant melanoidins. UV photodegradation, on the other hand, can degrade the colour causing melanoidins leading to complete colour removal after a short duration of irradiation. However, the UV process is energy intensive and incapable of effective TOC reduction. For effective MWW treatment, these two processes can be integrated such that 
UV photodegradation is applied as a post-treatment to AD. In this system, the $\mathrm{AD}$ will first remove the high organic content followed by colour removal by the UV process. This integrated process, however, needs to be optimised to determine the best operational and combinational factors. Evaluating the overall energy demand of such a system is also important in determining whether the bioenergy produced from the AD process can be used to supplement the energy requirement of the integrated system.

Acknowledgements This work was financially supported by Water Research Commission (WRC, Project no. K5/2388), South Africa.

\section{Compliance with ethical standards}

Conflict of interest On behalf of all authors, the corresponding author states that there is no conflict of interest.

\section{References}

Acharya BK, Mohana S, Madamwar D (2008) Anaerobic treatment of distillery spent wash-a study on upflow anaerobic fixed film bioreactor. Bioresour Technol 99:4621-4626. doi:10.1016/j. biortech.2007.06.060

Apollo S, Onyango MS, Ochieng A (2013) An integrated anaerobic digestion and UV photocatalytic treatment of distillery wastewater. J Hazard Mater 261:435-442. doi:10.1016/j.jhazmat.2013. 06.058

Arany E, Láng J, Somogyvári D, Láng O, Alapi T, Ilisz I, GajdaSchrantz K et al (2014) Vacuum ultraviolet photolysis of diclofenac and the effects of its treated aqueous solutions on the proliferation and migratory responses of Tetrahymena pyriformis. Sci Total Environ 468-469:996-1006. doi:10.1016/j. scitotenv.2013.09.019

Arimi MM, Zhang Y, Götz G, Kiriamiti K, Geißen SU (2014) Antimicrobial colorants in molasses distillery wastewater and their removal technologies. Int Biodeterior Biodegrad 87:34-43. doi:10.1016/j.ibiod.2013.11.002

Arnaiz C, Buffiere P, Elmaleh S, Lebrato J, Moletta R (2003) Anaerobic digestion of dairy wastewater by inverse fluidization: the inverse fluidized bed and the inverse turbulent bed reactors. Environ Technol 24:1431-1443. doi:10.1080/09593330309385687

Bechambi O, Najjar W, Sayadi S (2015a) The nonylphenol degradation under $\mathrm{UV}$ irradiation in the presence of $\mathrm{Ag}-\mathrm{ZnO}$ nanorods: effect of parameters and degradation pathway. J Taiwan Inst Chem Eng. doi:10.1016/j.jtice.2015.11.017

Bechambi O, Sayadi S, Najjar W (2015b) Photocatalytic degradation of bisphenol $\mathrm{A}$ in the presence of $\mathrm{C}$-doped $\mathrm{ZnO}$ : effect of operational parameters and photodegradation mechanism. J Ind Eng Chem 32:201-210. doi:10.1016/j.jiec.2015.08.017

Behzadnia A, Montazer M, Rad MM (2015) Simultaneous sonosynthesis and sonofabrication of $\mathrm{N}$-doped $\mathrm{ZnO} / \mathrm{TiO}_{2}$ core-shell nanocomposite on wool fabric: introducing various properties specially nano photo bleaching. Ultrason Sonochem 27:10-21. doi:10.1016/j.ultsonch.2015.04.017

Bel Hadjltaief H, Ben Zina M, Galvez ME, Da Costa P (2016) Photocatalytic degradation of methyl green dye in aqueous solution over natural clay-supported $\mathrm{ZnO}-\mathrm{TiO}_{2}$ catalysts. J Photochem Photobiol A Chem 315:25-33. doi:10.1016/j.jphoto chem.2015.09.008
Chandra R, Naresh R, Rai V (2008) Melanoidins as major colourant in sugarcane molasses based distillery effluent and its degradation 99:4648-4660. doi:10.1016/j.biortech.2007.09.057

Chavan MN, Kulkarni MV, Zope VP, Mahulikar PP (2006) Microbial degradation of melanoidins in distillery spent wash by an indigenous isolate. Indian J. Biotechnol 5:416-421

Chen Y, Cheng JJ, Creamer KS (2008) Inhibition of anaerobic digestion process: a review. Bioresour Technol 99:4044-4064. doi:10.1016/j.biortech.2007.01.057

De Vrieze J, Hennebel T, Van den Brande J, Bilad RM, Bruton TA, Vankelecom IFJ, Verstraete W, Boon N (2014) Anaerobic digestion of molasses by means of a vibrating and non-vibrating submerged anaerobic membrane bioreactor. Biomass Bioenergy 68:95-105. doi:10.1016/j.biombioe.2014.06.009

Drosg B (2013) Process monitoring in biogas plants. International Energy Agency Bioenergy, France. ISBN 978-1-910154-03-8

Habib A, Shahadat T, Bahadur NM, Ismail IMI, Mahmood AJ (2013) Synthesis and characterization of $\mathrm{ZnO}-\mathrm{TiO}_{2}$ nanocomposites and their application as photocatalysts. Int Nano Lett 3:1-8. doi:10.1186/2228-5326-3-5

Ibn Abubakar BSU, Ismail N (2012) Anaerobic digestion of cow dung for biogas production. ARPN J Eng Appl Sci 7:169-172

Jackson-Moss C, Duncan J (1990) The effect of iron on anaerobic digestion. Biotechnol Lett 154:149-154. doi:10.3846/mla.2011. 97

Jai Shankar Pillai HP, Ananth Nag B, Girish K, Puttaiah ET (2012) Biodegradation of solid waste molasses from Aranthangi sugar industry, Tamilnadu by using Aspergillus niger. Intern J Environ Sci 1:289-293

Jiang H, Yan P, Wang Q, Zang S, Li J, Wang Q (2013) Highperformance $\mathrm{Yb}, \mathrm{N}$, P-tridoped anatase- $\mathrm{TiO}_{2}$ nano-photocatalyst with visible light response by sol-solvothermal method. Chem Eng J 215-216:348-357. doi:10.1016/j.cej.2012.10.082

Jonidi-Jafari A, Shirzad-Siboni M, Yang JK, Naimi-Joubani M, Farrokhi M (2015) Photocatalytic degradation of diazinon with illuminated $\mathrm{ZnO}-\mathrm{TiO}_{2}$ composite. J Taiwan Inst Chem Eng 50:100-107. doi:10.1016/j.jtice.2014.12.020

Li A, Li X, Yu H (2011) Effect of the food-to-microorganism (F/M) ratio on the formation and size of aerobic sludge granules. Process Biochem 46:2269-2276. doi:10.1016/j.procbio.2011.09. 007

Liang Z, Wang Y, Zhou Y, Liu H (2009) Coagulation removal of melanoidins from biologically treated molasses wastewater using ferric chloride. Chem Eng J 152:88-94. doi:10.1016/j.cej.2009. 03.036

Liao DL, Badour CA, Liao BQ (2008) Preparation of nanosized $\mathrm{TiO}_{2} /$ $\mathrm{ZnO}$ composite catalyst and its photocatalytic activity for degradation of methyl orange. J Photochem Photobiol A Chem 194:11-19. doi:10.1016/j.jphotochem.2007.07.008

Liu G, Wang L, Yang HG, Cheng HM, (Max) Lu GQ (2010) Titaniabased photocatalysts - crystal growth, doping and heterostructuring. J Mater Chem 20:831-843. doi:10.1039/B909930A

Liu M, Zhu H, Dong B, Zheng Y, Yu S, Gao C (2013) Submerged nanofiltration of biologically treated molasses fermentation wastewater for the removal of melanoidins. Chem Eng J 223:388-394. doi:10.1016/j.cej.2013.02.107

Mohana S, Acharya BK, Madamwar D (2009) Distillery spent wash: treatment technologies and potential applications. J Hazard Mater 163:12-25. doi:10.1016/j.jhazmat.2008.06.079

Mozaffari S, Ranjbar M, Kouhestanian E, Salar Amoli H, Armanmehr M (2015) An investigation on the effect of electrodeposited nanostructured $\mathrm{ZnO}$ on the electron transfer process efficiency of $\mathrm{TiO}_{2}$ based DSSC. J Hazard Mater 40:310-318. doi:10.1016/j. tsf.2007.08.113 
Navgire M, Yelwande A, Tayde D, Arbad B, Lande M (2012) Photodegradation of molasses by a $\mathrm{MoO}_{3}-\mathrm{TiO}_{2}$ nanocrystalline composite material. Chin J Catal 33:261-266

Ohtani B (2010) Photocatalysis A to Z-what we know and what we do not know in a scientific sense. J. Photochem Photobiol C Photochem Rev 11:157-178. doi:10.1016/j.jphotochemrev.2011. 02.001

Oller I, Malato S, Sánchez-pérez JA (2011) Combination of advanced oxidation processes and biological treatments for wastewater decontamination-a review. Sci Total Environ 409:4141-4166. doi:10.1016/j.scitotenv.2010.08.061

Otieno BO, Apollo SO, Naidoo BE, Ochieng A (2016) Photodegradation of molasses wastewater using $\mathrm{TiO}_{2}-\mathrm{ZnO}$ nanohybrid photocatalyst supported on activated carbon. Chem Eng Commun 6445:1443-1454. doi:10.1080/00986445.2016.1201659

Otieno BO, Apollo SO, Naidoo BE, Ochieng A (2017) Photodecolorisation of melanoidins in vinasse with illuminated $\mathrm{TiO}_{2}-\mathrm{ZnO} /$ activated carbon composite. J Environ Sci Heal Part A. doi:10. 1080/10934529.2017.1294963

Satyawali Y, Balakrishnan M (2008) Wastewater treatment in molasses-based alcohol distilleries for COD and color removal: a review. J Environ Manag 86:481-497. doi:10.1016/j.jenvman. 2006.12.024
Shu Z, Bolton JR, Belosevic M, Gamal M, Din E (2013) Photodegradation of emerging micropollutants using the medium-pressure $\mathrm{UV} / \mathrm{H}_{2} \mathrm{O}_{2}$ advanced oxidation process. Water Res 47:2881-2889. doi:10.1016/j.watres.2013.02.045

Wang X, Wu Z, Wang Y, Wang W, Wang X, Bu Y, Zhao J (2013) Adsorption-photodegradation of humic acid in water by using $\mathrm{ZnO}$ coupled $\mathrm{TiO}_{2} /$ bamboo charcoal under visible light irradiation. J Hazard Mater 262:16-24. doi:10.1016/j.jhazmat.2013. 08.037

Wilkie AC, Riedesel KJ, Owens JM (2000) Stillage characterization and anaerobic treatment of ethanol stillage from conventional and cellulosic feedstocks. Biomass Bioenergy 19:63-102. doi:10.1016/S0961-9534(00)00017-9

Xu Y, Zhuang Y, Fu X (2010) New insight for enhanced photocatalytic activity of $\mathrm{TiO}_{2}$ by doping carbon nanotubes: a case study on degradation of benzene and methyl orange. J Phys Chem C 114:2669-2676. doi:10.1021/jp909855p

Zhang P, Shao C, Li X, Zhang M, Zhang X, Sun Y, Liu Y (2012) In situ assembly of well-dispersed Au nanoparticles on $\mathrm{TiO}_{2} /$ $\mathrm{ZnO}$ nanofibers: a three-way synergistic heterostructure with enhanced photocatalytic activity. J Hazard Mater 237-238:331-338. doi:10.1016/j.jhazmat.2012.08.054 